\title{
EDUCATION FOR THE DEAF IN MALAWI
}

Brother Hortensius Meeuws

\author{
Montfort Teacher Training College, Malawi
}

When I arrived in the country, in 1963, there was no special provision for the education of deaf children. Being the only person with a rather long experience in this particular field and with the necessary qualifications, I thought it my duty to undertake something for the deaf children in this country. However, no funds were available at that time, so I had to confine myself to incidental and private lessons.

In February 1967 I happened to have a meeting with $\mathrm{Mr}$. John Chadwick, the Director of the Commonwealth Foundation, on a visit to Malawi. With him and other interested parties I discussed the possibilities of financial aid from the Commonwealth Foundation for this particular project. lnitially the Commonwealth Foundation was prepared to help, but a simple start had to be made first to prove the feasibility of the project.

In March 1968 one unit with five children was opened in a borrowed classroom in Montfort Teacher Training College. In 1969 we had to open a second classroom in the College, and we had fourteen pupils in the two classrooms together. It proved that the number of applications for a place in the first school for deaf children in Malawi was rapidly increasing, and we had to make plans for our own school buildings. Particularly, the room for temporary boarding facilities was up to its maximum, and therefore hostels had to be planned together with the school, and also houses for the teachers.

From the first start we began training some local teachers for the education of the deaf. This had now grown out to a full teacher trainirig course for teachers of the deaf at Montfort College, which course is also open for teachers of other countries. A prospectus of this course has recently been issued and sent to different countries. The course is run by four expatriate tutors.

In June 1969 the Commonwealth Foundation offered an overall award in the sum of $\$ 37,150$. This award was made up of the following elements:

(a) Visits twice-yearly over a five year period to Malawi by British E.N.T. consultants £10,650

(b) Construction of deaf teacher training school-cum-clinic

(c) Purchase of equipment for school and clinic

$£ 20,000$

£ 5000

(d) Transport for visiting surgical teams over a five year period

$£ 1,500$

The building plans for the school, hostels, audiology testing centre and teachers' houses were made by an appointed architect in Blantyre. We realised from the beginning that the building grant of the Commonwealth Foundation would not cover the cost of the total plan, and therefore we had 
to find additional funds to be able to finish the buildings.

The buildings of the school consist of: one classroom block with three classrooms and one handicraft room, a second classroom block with three classrooms, a service block with two individual speech training rooms, a staffroom and toilets for the staff, boys and girls. In addition to this a special block was built as the audiology testing centre, which contains a director's office, a big testing room which also serves as an auditory training room and assembly hall for the children, a small observation room and a laboratory.

Each classroom was designed for approximately 8 children. They are light and pleasant and well ventilated. Four classrooms are equipped with a Philips group hearing aid, and two classrooms are equipped with the inductive loop system. They are as far apart from one another as possible to prevent overlapping of the signal. The group hearing aid is installed in specially designed horseshoe tables with the amplifier built-in in the teacher's desk. In addition, each classroom is equipped with a loop-system for special purposes.

The testing centre is equipped with a Peters AP5 Audiometer, which is installed in the observation room with a record player and a tape recorder. From the observation room signals can be given to the testing room via several loudspeakers and an intercom system for free-field testing. Apart from that a portable audiometer is available for fieldwork. In the laboratory equipment is installed for making earmoulds and repairing hearing aids.

The hostels are divided into four units, each self-containing, and each hostel unit offers place for approximately 16 children. The hostels are run by local African Religious Sisters, who receive a special training. They also attend classes two days per week in the school, and they are even allowed to give an occasional lesson. The four hostel units have one central kitchen.

For the African teachers four houses have been built so far on the same premises. We hope to get four more houses from the Malawi Government. The buildings are all supplied with electricity from town (we are about 15 miles from Blantyre) and have their own water supply from a borehole and a handpump. The borehole is operated with an automatic electric pump and a storage tank, so that there is a continuous water supply.

Part of the Project for The Education For the Deaf in Malawi is the twice-yearly visit of an E.N.T. consultant from Britain. Malawi does not have its own E.N.T. specialist. The visiting specialist is usually based at the Queen Elisabeth Central Hospital in Blantyre, but during his stay he also visits bigger centres elsewhere in the country, like Zomba and Lilongwe. In order to give him full opportunity for operations a special operation microscope has been purchased from a Commonwealth equipment grant. Several ear operations have been already successfully completed.

The testing centre not only serves the school for deaf children, but also anybody with hearing complaints. In addition aircraft pilots are tested here twice per year. Two members of the expatriate staff are qualified audiologists. Where necessary and possible, individual patients are helped with a hearing aid. About 40 hearing aids have been handed out so far. African patients who are not able to pay get them free of charge. They have to pay only for replacements of batteries, cords and receivers. 
The education of the children is free. The Government gives a grant for boarding and tuition. The Government is also responsible for the running costs of the existing school. During the last four years we have collected a good deal of information about the incidence of deafness in Malawi, and,although exact numbers are not yet available, we think it justified to establish three schools for the deaf in the country: one in the south, as the central training base for teachers, one in the north and one in the centre. But first we have to build the existing school properly, and we are planning already a third classroom block, to bring the total number of classrooms up to ten. The next step will certainly be vocational training, but all this will take time, since we have only just started. 